\title{
AS TEORIAS CONSPIRATÓRIAS NOS ESTADOS UNIDOS: DO CITZENS COUNCILS E DA JBS A DONALD TRUMP
}

\author{
Ariel Finguerut* \\ Marco Aurélio Dias de Souza**
}

\begin{abstract}
Resumo: Este artigo discute duas organizações políticas dos EUA da década de 1950/1960, o Citizens Councils (CCs) e a The John Birch Society (JBS). Nossa proposta é entender como a retórica "populista" / "americanista" historicamente se disseminou e se propagou chegando ao presente com Donald Trump, entendendo-o como um fenômeno contemporâneo cujo governo - no primeiro mandato - apoia de forma velada e com retórica confusa, às vezes apoiando supremacistas raciais, defendendo ideias nostálgicas e propagando cotidianamente teorias conspiratórias. Para além da retórica, Trump adota teses populistas como leis mais rígidas anti-imigração, políticas antirefugiados e restrições aos requerentes de asilo, além de propor acelerar a construção do muro na fronteira mexicana.
\end{abstract}

Palavras-chave: The Citizens Councils; John Birch Society; Donald Trump; teorias conspiratórias.

\begin{abstract}
This article discusses two organizations from the 1950s and 1960s, the Citizens Councils (CCs) and the John Birch Society (JBS). Our propose is to understand how the "populist" / "americanist" rhetoric historically disseminated and propagated as an trajectory of ideas and political movements that allows us to discuss Donald Trump, understanding him as a contemporary phenomenon whose government - in the first term - has the supports of segregationist and white supremacists and propagates conspiracy theories by taking up populist theses of Americanism and proposing, both rhetorically and in the form of laws, a new era for the United States, with rigid antiimmigration laws, anti-refugee policies and restrictions on asylum seekers. and building a wall on the Mexican border.
\end{abstract}

Keywords: The Citizens Councils; The John Birch Society; Donald Trump; conspiracies theories.

\section{Introdução}

A pergunta e o propósito deste artigo partem de entender como a pós-verdade explica não apenas o comportamento de Trump, mas, também, como a estratégia de manipular conspirações e mentiras como ferramenta de embate político sempre esteve presente na tradição política estadunidense. Segundo Kakutani (2018) a pós-verdade como fenômeno contemporâneo pode ser entendido de forma sintética como uma iniciativa, um comportamento que parte do descaso pelos fatos, valorizando e manipulação das emoções (em detrimento do apelo à razão) a se apoiando não em fatos empíricos ou históricos mas em narrativas, ideias e teorias sem comprovação quando não são meras mentiras contadas como " novas descobertas" ou com o respaldo de uma suposta "maioria". Só Donald Trump em seu primeiro ano como presidente dos EUA, declarou, propagou,

\footnotetext{
* Doutor em Ciência Política (Universidade Estadual de Campinas). E-mail: arielfing@gmail.com

** Doutorado em Programa de Pós-Graduação em Sociologia pela Universidade Estadual Paulista Júlio de Mesquita Filho, Brasil. Professor Adjunto da Universidade Federal de Sergipe/ Itabaiana, Brasil E-mail: dias_dias_@hotmail.com
} 
mentiu 2140 vezes segundo o The Washington Post (apud; Kakutani (2018)). O uso da mentira na política não uma novidade, o tema é clássico na filosofia política contudo, o desafio trazido por Trump - e outros líderes populistas contemporâneos - é a guerra contra a linguagem, buscando definir a realidade em seus próprios termos. Este processo abre as portas do poder para conspiradores e suas mais diversas teorias conspiratórias; como também ouve negacionistas (das mais diversas causas) e compromete a já frágil democracia, direcionando políticas públicas ao sabor dos mais diversos lobbies, e alimenta uma constante campanha política que se apoia na manipulação da dúvida e flerta constantemente com o caos social.

Para isso, o artigo parte da leitura de Snyder (2018) e de seu entendimento da eleição de Donald Trump Jr. como fruto de uma estratégia de transformação do mundo, iniciada na Rússia, responsável pela transposição do que o autor denominou de política da inevitabilidade para adentrar em uma política da eternidade. Dentro dessa leitura, a concepção de política da inevitabilidade se produziria a partir da crença que o mundo se tornaria um lugar melhor, ou seja, estabelecia que caminhos como a ciência, a democracia, o livre-mercado e a ideia de verdade (relacionada a ideia de factualidade), separados ou conjuntamente, trariam a constatação de que as crises deveriam ser encaradas como passageiras e que a esperança em um futuro cada vez melhor seria inevitável.

Essa ideia de inevitabilidade manteve-se hegemônica entre os anos 1980 e o final da última década e resultou no desmonte do Estado de bem-estar social, no crescimento da desigualdade social e na ampliação da concentração de renda, transmitindo contradições que seriam bases para a ideia de política da eternidade. Como proposto pelo autor, dentro da lógica da eternidade se estabeleceria a percepção de que o mundo estaria amarrado a uma constante crise, motivada pela perda de uma inocência simbólica (mítica). A solução proposta pelos adeptos dessa política, seria negar a essência da inevitabilidade, rejeitando a democracia, a ciência, a fatualidade e, assim, transferir todas as decisões à um líder, forte o suficiente para se sobrepor e estabelecer o que era relevante, verdadeiro, puro e, até mesmo, quem seria digno ou indigno de fazer parte da ideia de povo.

No caso estadunidense, Trump seria construído pela política da eternidade, em torno de sua figura se estabeleceria a busca por referências míticas sobre o que representaria ser americano que desembocaram em características como o americanismo, o excepcionalismo e em um extrapolamento de uma certa tradição conspiratória estabelecidas na margem da democracia do país.

Ao perceber a relevância da conspiração para a construção dessa lógica de política de eternidade para a eleição e administração Trump, o artigo preocupa-se em resgatar um pouco das raízes históricas dessa tradição ao se debruçar sobre a passagem da década de 1950 para os anos de $1960^{1}$ e encontrar dois movimentos políticos de caráter populistas/americanistas com forte enraizamento social, tanto no Sul dos EUA como no Norte e que utilizaram das conspirações e de uma comunicação direta como sua base para serem efetivos e ganharem peso e presença no jogo político: A The John Birch Society (JBS) e a Citizens Councils (CCs).

A CCs surgiu em 1954 como uma reação à decisão da Suprema Corte dos EUA, a Brown v. Board of Education of Topeka cujo debate teve início em 09/12/52 e chegou a uma decisão em 17/05/54. Em Indianola, Mississippi, o juiz Thomas P. Brady escreveu em resposta a decisão um texto panfletário intitulado Black. Monday, em referência ao dia da decisão. No texto publicado em 11/07/54, o juiz conclamou seus concidadãos a resistir a decisão de Washington D.C. e a defender o modo de vida sulista no qual a segregação não poderia ser separada. Como resposta, no mesmo

\footnotetext{
${ }^{1}$ Autores como Chip Berlet and Matthew N. Lyons (2000) e Sarah Diamond (1994) fizeram a apresentam um estudo sistemático e o mais completo possível de movimentos e atores da direita e da extrema direita, incluindo movimentos conspiratórios de víeis intelectual ou anti-intelectual.
} 
dia, na sede da prefeitura da cidade, Brady discursou e reuniu simpatizantes criando o Citizens Councils. Em menos de um ano o grupo se espalhou pelos estados sulistas, chegando a 250 sedes e 60 mil membros. Em 1956 já estavam em 30 estados e com 250 mil filiados.

Como aponta Lichtman (2008) a CCs foi um marco de mobilização e teve um êxito que até então somente o KKK dos anos de 1920 tinha alcançado no sul dos EUA. Mas ao contrário do KKK e sua marca de violência, da cultura dos linchamentos e intimidação a CCs se propunha a agir como uma espécie de lobby, seu objetivo era resistir a integração ganhando a opinião pública e o apoio das classes médias, pressionando politicamente pela manutenção da segregação racial. Se no passado participar do KKK era algo as escondidas, ir a uma reunião do CCs era um evento social onde se encontrariam pequenos empresários, comerciantes, etc. O grupo durou até meados dos anos de 1970 sem uma data precisa como marco e foi influente no endurecimento da legislação pró-segregação no Mississipi, mas falhou no objetivo de impedir o avanço dos Direitos Civis na legislação nacional.

Entre 1954 e 1973 a CCs publicou um Boletim de Notícias bem como uma revista, a The Citizen (publicada até 1979) que serão o foco de análise nas sessões seguintes deste artigo. Esta pesquisa no acervo do grupo ajuda a entender não só a estratégia do grupo, seu contexto histórico e, como já anunciado, será a chave para pensarmos a própria estratégia e retórica emprega nos dias atuais por Donald Trump. Este material está disponível e foi digitalizado pela University of Mississippi ${ }^{2}$.

Nosso outro objeto de pesquisa foi a The John Birch Society (JBS). Criada em 1958 em Indianapolis, Indiana, por Robert W. Welch Jr., a organização surgiu como resposta a perda de credibilidade e morte do senador anticomunista Joseph Raymond McCarthy em 1957. Sua fundação, segundo Wilcox (1988), se deu a partir da união entre uma série de teorias conspiratórias que denunciava a infiltração comunista no establishment liberal e estimulava uma postura anti-establishment e antigoverno federal. Como objetivo central, a organização pretendia denunciar que soviéticos controlavam grande parte do governo dos EUA, lideravam os movimentos por direitos civis e sindicatos e seriam responsáveis pelos eventos e conflitos mais traumáticos ocorridos no país. Dentro dessa lógica, o assassinato de Kennedy, as revoltas populares ocorridas durante os protestos pelos direitos civis e, até mesmo, a morte do próprio senador McCarthy, por cirrose, eram identificados como resultados de ações conspiratórias de comunistas ${ }^{3}$.

O John Birch que dá nome a organização foi um missionário e piloto das forças aéreas dos EUA preso e assassinado na China em 1945 durante a $2^{\text {a }}$ Guerra Mundial. Para o fundador da JBS, Robert Welch, o caso do missionário morto na China seria de um mártir, a primeira perda da Guerra contra o comunismo (o que viria a ser a III Guerra Mundial) e que o governo dos EUA tentou encobrir e desqualificar.

A JBS cresceu rapidamente, em dois anos criou uma grande organização de base, espalhada por diferentes estados com orçamento passando da casa dos milhões em 1960 contando com mais cem mil filiados ${ }^{4}$. Segundo a reportagem de Bundschu (1961) para o Washington Dally News a organização possuía uma rede de financiamento que consistia no pagamento de uma taxa anual de 24 dólares para homens e 12 dólares para as mulheres, ou ainda, estabelecia a possibilidade de

2 Cf. em < http://clio.lib.olemiss.edu/cdm/landingpage/collection/citizens > Acessado em 17/09/2019.

3 Mulloy (2014) mostra que os membros da JBS consideravam a possibilidade de assassinato, como uma tentativa de calar as vozes que alertavam o país sobre a infiltração soviética.

${ }^{4} \mathrm{O}$ número de membros da organização não é preciso, devido a fragmentação e o esforço de seus membros para criar uma atmosfera secreta. 
pagamento de uma taxa única de 1000 dólares para se tornar membro vitalício. O dinheiro arrecadado era utilizado para a manutenção da organização, financiamento de campanhas publicitárias e mobilizações políticas e o pagamento de 35 funcionários espalhados nos comitês ao redor do país.

A organização alcançou destaque ao trazer para suas fileiras um novo público da direita radical, visto que, como apontou Stone (1974), seus membros se diferenciavam das características descritas pelos principais autores que estudavam o tema. Eles não eram exclusivamente homens, brancos, pobres, de idade mais avançada, fundamentalistas protestantes, indivíduos racistas e autoritários. Os membros da Birch eram, em sua maioria, o oposto disso, eram jovens, bem educados, com bons empregos e não ligados a vertentes religiosas fundamentalistas, engajavam-se pelo caráter de política direta que a organização proporcionava e pela sensação de possibilidade de atuar na política em tempos de medo e ameaça de um rival poderoso 5 .

Como mostra Mulloy (2014) a característica comum a todos os comitês da organização estava a estrutura piramidal, ao qual, Robert Welch, ocupava a posição de líder do comitê central e abaixo dele se estruturavam os líderes dos comitês central e locais e outros participantes. A centralidade da organização em Welch está presente desde sua formação, isso fica claro quando no livro base da organização, Welch (1963) descreveu que os outros 11 primeiros membros da JBS estavam ali para assessorá-lo em suas decisões e substituí-lo em caso de sua morte ou desaparecimento ${ }^{6}$.

De acordo com Grupp Jr. (1971) a cada 5 membros da organização, 3 declaravam que sua filiação estava associada a possibilidade de conviver com pessoas com visões de mundo e preocupações ideológicas semelhantes as suas. O sentimento de engajamento criado pela luta contra um inimigo comum e pelo constante discurso sobre o papel educacional da JBS forjava um forte sentimento de ligação entre seus membros, o que era reforçado pelo estabelecimento de metas de curto alcance por suas lideranças locais, que estimulavam um sentimento constante de objetivos alcançados pelos seus membros.

Ao longo dos anos de 1960 a JBS foi articuladora central de candidatos conservadores tanto nos estados como na disputa nacional. Embora em meio a campanha presidencial de Barry Goldwater tenha sido denunciada por William F. Buckley, Jr. como símbolo da velha direita e nas décadas seguintes, Robert Welch passasse a ser visto como um radical por parte da grande imprensa e de lideranças dos partidos políticos, a JBS segue ativa e Welch se manteve à frente da organização por duas décadas até sua morte em 1985.

A JBS além de uma série de livros, panfletos e artigos tem uma revista, a American Opinion (desde 1985) que sucedeu as publicações anteriores: American Opinion e The Review of the News. Parte deste material está disponível no próprio site da JBS. Especificamente para esse artigo utilizase como fontes: o livro The Politician, publicado pela primeira vez em 1963 e que desde 1958 era distribuído em forma de manuscrito por Welch e o livro The Blue Book of The John Birch Society, com sua primeira publicação em 1959, que condensa os ideais da organização. Junto a esses dois livros, o artigo traz ao debate dois filmes produzidos pela JBS: o primeiro The Truth in Time (1966), ao qual, o líder da Birch discursa por cerca de 1 hora e 20 minutos sobre a história da conspiração coletivista no mundo ${ }^{7}$ e o segundo intitulado Anarchy, U.S.A. (1966), um documentário financiado

\footnotetext{
${ }^{5}$ Como aponta Wilcox (1988), o próprio Welch afirmava que 40\% da organização era composta por católicos e a organização recebia em suas fileiras membros secularistas.

6 Já no texto de fundação a perspectiva conspiratória de que os que se levantavam contra o comunismo eram possíveis alvos nos EUA é bem visível.

7 O objetivo do filme é ser um material para ser distribuído em VHS e conseguir levar a mensagem da organização para os lares estadunidense.
} 
pela organização e dirigido por Edward Griffin sobre a infiltração comunista nos movimentos por direitos civis. Para além do material produzido diretamente por Welch, o artigo busca apoio em um rico material extraídos da Ernie Lazar Collection ${ }^{8}$, acervo montado e disponibilizado online via Freedom of Information Act (FOIA) que mediante solicitação judicial tem acesso a material até então não disponível ou com acesso restrito.

Nesse sentido, o artigo se dividirá em quatro partes a partir dessa introdução: a primeira que relaciona teorias conspiratórias e pós-verdade a trajetória política do conservadorismo e novo conservadorismo estadunidense (até a chegada no governo Trump e a dificuldade de enquadra-lo como um político inserido nesse espectro). Em seguida aborda, nas duas próximas passagens, a presença das teorias da conspiração na JBS e na CCs, concentrando o esforço para entender sua importância na construção de mobilização política. E, por fim, desenvolverá as conclusões finais, com o intuito de reforçar a importância do legado das articulações e estratégias desses movimentos para que se dê conta da compreensão do cenário político atual.

\section{Raízes Históricas do “Americanismo”}

Toda conspiração é uma forma de ataque ou contra-ataque a uma suposta ou real movimentação política. Revoluções podem acontecer como reação a uma ameaça conspiratória, guerras podem estourar por que supostos segredos foram revelados e a espionagem, que não deixa de ser uma forma de conspirar contra um Estado ou ator político, sempre fez parte da história dos Estados-Nacionais, assim como, as guerras e a diplomacia.

A conspiração funciona numa lógica exclusivista. A narrativa clássica das conspirações é de um pequeno grupo ${ }^{9}$, com afinidades que podem ser ideológicas, étnicas, religiosas ou políticas que manipula recursos políticos, financeiros, ideológicos para impor suas ideias ou agenda há um público maior, amplo que por definição estaria sendo enganado, trapaceado, roubado. Como bem argumentou o psicólogo Rob Brotherton (2018) a conspiração é uma espécie de alimento para a mente paranoica e todos nós, para sobreviver, precisamos em alguma medida sermos paranoicos. A diferença em se tratando das conspirações é que elas encontram alguém mais disposto a duvidar e a buscar explicações alternativas para o que muitas vezes não se consegue entender ou que tem múltiplas explicações possíveis.

Este público que se alimenta de conspirações é também aquele que chega mais perto de conspirar de fato. Nancy Rosenblum (2019) argumenta que políticos, grupos e movimentos que denunciam conspirações são aqueles que usam desta manipulação para conseguirem legitimidade, seguidores ou, em síntese, poder. Manipular conspirações é, em suma, manipular o medo de uma parcela das pessoas e da população. E assim como um medo pode levar a outro, uma conspiração tende a outra, criando uma rede de pequenas conspirações que quando vistas em seu todo tem geralmente uma explicação que volta a ser pequena.

Dentro dessa lógica, cada momento histórico tem seus medos e suas conspirações, assim como, possuem os grupos, movimentos e políticos que supostamente "denunciam" estas conspirações. $\mathrm{O}$ antissemitismo no período entre guerras teve eco em figuras como o governador da Louisiana (1928 - 1932) e senador (1932 - 1935) Huey Long. Outro que manipulava conspirações

\footnotetext{
8 Cf. < https://archive.org/details/ernie1241_jbs > Acessado em 17/09/2019.

9 Sustein e Vermeule (2009) apontam que são atribuídos a esse grupo algumas características extraordinárias que seriam utilizadas por eles pra esconder grandes segredos ou manipular os outros.
} 
judaicas e alertava para os riscos dos judeus era o padre e radialista popular Charles Coughlin ${ }^{10}$. Nos anos de 1950, eram populares as conspirações que apontavam os comunistas, e a URSS como bode expiatório, como o grupo que estaria infiltrado e manipularia os rumos do governo dos EUA e do mundo. Grupos como o The John Birch Society (JBS) cresceram denunciando a conspiração vermelha e o senador Joseph McCarthy (representante do estado de Wisconsin entre 1947 e 1957) soube manipular este medo como chefe da comissão da "House of Un-American Activities". McCarthy acusou 143 pessoas $^{11}$ de envolvimento com o partido ou com o movimento comunista nos EUA, entre artistas, escritores, militares, funcionários públicos, etc.

Os anos de 1960 marcaram a década de inflexão e formação de uma nova direita nos EUA. O conservadorismo até então tinha duas linhas de mobilização. Uma parlamentar que lutava contra as políticas e desdobramentos do chamado New Deal e possuía um caráter mais isolacionista na política externa. E outra que englobava movimentos nativistas e supremacistas raciais - em referência a movimentos como o Know Nothing (1850) responsáveis pelas mobilizações anti-imigrantes que influenciaram o The Chinese Exclusion Act de 1882, as diferentes ondas de mobilização do Ku Klux Klan (KKK) e o American First (1940) que defendia uma américa branca e a não entrada dos EUA na luta contra o nazifascismo.

Nesse sentido, o conservadorismo até 1959 era pautado por teorias racistas e contra minorias, seja contra negros, antissemitas, xenofóbicas e anticatólicas. Dentro desse cenário, os anos 1950 marcaram uma geração de transição entre o que ficou conhecido como "velha direita" para uma "nova direita". Entre esses movimentos estavam grupos como a John Birch Society, Life Line, The Christian Crusade, Liberty Lobby e Christian Anti-Comunism Crusade que disseminavam por todo o país material e propaganda conspiratória e a partir delas traziam um maior grau de sofisticação ao debate conservador. Contudo, se existia um esforço por parte dessas organizações de se colocarem com algo novo, ao ponto de, algumas delas abandonarem os argumentos de raça biológica, em grande parte do tempo suas mobilizações serviam de respaldo e motivação para grupos como o KKK organizarem e realizarem ações violentas, incluindo assassinato, linchamento e intimidação.

A chamada nova direita também não excluiu a conspiração de seu discurso, afinal, nos anos de 1960 fez grande sucesso a obra de Phyllis Schlafly, A Choice Not An Echo (1964) na qual a ideia de uma conspiração financeira global forçaria os EUA a defender interesses e adotar posturas internacionais que seriam contrários a seus reais interesses. Schlafly denuncia a manipulação do grupo Bilderberg $^{12}$ que levaria os EUA a assumir compromissos globais, como a liderança nas Nações Unidas e explicaria por que candidatos genuinamente conservadores, como Barry Goldwater, candidato derrotado em 1964, teriam dificuldade de vencer.

Nos anos de 1970 ganhou força o medo do declínio do poder e da cultura dos EUA. Autores tanto a direita como a esquerda denunciavam o risco de uma catástrofe ecológica, nuclear ou, mesmo passado o "verão do amor" do final dos anos de 1960, os americanos estariam fadados ao

10 O padre Coughlin tinha uma audiência que chegava a 30 milhões entre 1930 e 1939. Cf. Entrevista com autor Donald Warren do livro Radio Priest: Charles Coughlin, The Father of Hate Radio, ed. Free Press, NYC. 2015. Disponivel em < https://www.c-span.org/video/?73853-1/radio-priest-charles-coughlin> Acessado em 12/09/2019.

1193 foram condenados. Cf. Biografia escrita por James Cross Giblin, The Rise and Fall of Senator Joe McCarthy, Ed. Clarion Books, NYC. 2009.

12 Grupo articulado pelo príncipe holandês Bernhard of Lippe-Biesterfeld que desde 1954 se reúne no hotel Bilderberg na cidade holandesa de Oosterbeek. São convidados líderes globais, empresários, banqueiros, investidores para discutir a conjuntura e os rumos da política global. Cf. site oficial em < https://bilderbergmeetings.org/ > Acessado em 12/09/2019. 
consumismo, ao niilismo e uma vida distante das promessas do "american way of life". Soma-se a este contexto cultural a volta do medo de uma invasão de imigrantes, a violência e o ressentimento da questão racial e a "ameaça" trazida pelo movimento feminista. Neste período de transição, entre os anos de 1960 para os anos 1970, as teorias conspiratórias deixaram o chamado mainstream conservador e ganharam perfil de movimentos sociais, alguns de perfil populista outros de perfil reacionário. Grupos como o Posse Comitatus surgiram em 1969, propondo que nada para além da jurisdição do condado poderia existir. O Estado americano seria tirânico e, portanto, as pessoas em seus condados deveriam se armar e se preparar para eventualmente a força, resistir ao governo dos EUA. O grupo em seu auge nos anos de 1970 chegou a ter 12 mil membros em mais de 50 cidades, 18 estados.

Enquanto intelectuais como William F. Buckley Jr, Russell Kirk, Daniel Bell, Irving Kristol, Richard Hofstadter, Nathan Glazer e Seymour Martin Lipset buscavam uma nova síntese para entender qual seria a base do Partido Republicano, o que seria ser conservador e quais movimentos políticos formariam a "Nova Direita", as teorias conspiratórias perderam protagonismo, foram relegadas a categoria de "anti-intelectualismo", "nativismo", " americanismo" ou " paleoconservadores".

O conservadorismo midiático e intelectual que nasceu com a ideia de uma Nova Direita fez que as conspirações se voltem contra o próprio mainstream, muitas vezes contra o próprio governo dos EUA. Nos anos de 1980 cresceram movimentos de milícias e de "patriotas" que se alimentam de conspirações que colocam o governo como inimigo, seja como aquele que quer coletar impostos indevidos ou aquele que quer desarmar a população ou mesmo promover uma carceragem em massa de pessoas ou que estaria promovendo uma perseguição racial aqueles que se opõem a integração e aos direitos civis.

Autores como Dan Smoot (1962), ele próprio um funcionário de carreira do FBI e ligado também a JBS denunciaram desde do final dos anos de 1960 a ideia de um "governo invisível", manipulado por grupos internacionalista como o Council on Foreign Relations (CFR) e argumentaram que o governo dos EUA não tinha legitimidade e agia contra o interesse de certas parcelas do povo.

O Liberty Lobby surgiu no final dos anos cinquenta e cresceu nos anos de 1960 denunciando os riscos de o Estado americano ceder, ser dominado por uma conspiração de "governo mundial". A ideia seria que os EUA estariam minando o poder dos estados, criando um regime autoritário e enfraquecendo a identidade americana em detrimento de uma nova identidade, não cristã e com diversidade racial. $\mathrm{O}$ antissemitismo deste caso é notório, visto que, autores como Francis Parker Yockey $^{13}$ argumentavam que os EUA eram governados por sionistas e que seria uma força política ainda mais nociva que a URSS.

Outra referência dos anos de 1970, como mostram Chip Berlet e Matthew N. Lyons (2000), foi Lyndon LaRouche. Um articulador político que foi central para a disseminação das teorias conspiratórias nos anos de 1980. Como estudante foi um militante de esquerda, participou e criou movimentos e publicações socialistas, mas, com o tempo, tornou-se um defensor do fascismo e foi um dos pioneiros no uso de propaganda com linguagem ambígua ou com uso de símbolos para transmitir uma mensagem de ódio ou de superioridade racial/cultural. LaRouche também tentou criar organizações e fundações para servir de fachada para espionagem ou para se esconder numa rede de atividades. Criou partidos políticos ${ }^{14}$, foi candidato, se aproximou de outros

13 Autor do livro Imperium (Ed. Abergele: The Palingenesis Project lançado originalmente em 1948)

14 Em 1973 o U.S. Labor Party, inicialmente um partido de orientação marxista, depois neofascista. 
partidos neofascistas europeus de forma a ser uma espécie de agente da desinformação, tentando muitas vezes cooptar ou copiar estratégias da esquerda.

Nos anos de 1990 o sentimento de um governo despótico e parasitado por agentes sionistas ou internacionalistas seguiu forte entre os grupos, milícias e movimentos conspiratórios. David Duke uma liderança do Klu Klux Klan $(\mathrm{KKK})$ da Louisiana seguiu alguns dos esquemas e estratégias de LaRouche e entrou para política, não falando abertamente de superioridade racial ou com posturas antissemitas, mas criticando as ações afirmativas ${ }^{15}$, prometendo "America First" e atacando o "lobby de Israel" que direcionaria os interesses dos EUA. Duke explorou por exemplo a denominação “ZOG - Zionist Ocupation Goverment” e propôs uma espécie de $3^{a}$ Posição ${ }^{16}$, nem exatamente capitalista nem comunista ${ }^{17}$. Como argumentam Berlet e Lyons (2000), a ideologia fascista que cresce nos EUA entre as décadas de 1970, 80 e 90 mescla elementos ambíguos do conservadorismo com uma postura que flerta também com propostas progressistas com viés antielitista.

Pat Buchanan um nome importante da comunicação e estratégia política do governo Nixon (1969 - 1974) tornou-se personagem central entre os paleoconservadores, desafiando George H. W. Bush nas primárias do partido Republicano em 1992. Buchanan retomou as ideias de ZOG e de America First e direcionou seus ataques aos chamados neoconservadores ${ }^{18}$ que defenderiam não só Israel, mas sobretudo a ideia de uma Pax Americana, e uma Nova Ordem Mundial. Buchanan também contrapôs sua plataforma nacionalista/America First ${ }^{19}$ ao que denominou de globalismo ${ }^{20}$. America First seria protecionista, isolacionista e anti-imperialista. Já o globalismo seria a defesa das fronteiras abertas, do casamento interracial, da diversidade, do feminismo e da educação secular humanista. O impacto que Buchanan conseguiu nas primárias de 92 o levou a tentar novamente nas primárias 96 e o fez sair candidato em $2000^{21}$ pelo partido Reform Party of the United States of America. Com respaldo intelectual da Samuel Francis ${ }^{22}$ (1947- 2005) e com milhões de votos das primárias do partido republicano, Buchanan marcou uma posição tanto em contraste ao conservadorismo - que defendia o livre mercado e a diversidade cultural dos EUA - com em relação à esquerda, na forma de um movimento progressista que ganhou força no partido democrata.

15 Duke criou por exemplo o NAAWP (National Association for the Advancement of White People) para fazer uma contraposição ao NAACP (National Association for the Advancement of Colored People)

16 Depois de tentar êxito pelas primárias do partido democrata, Duke concorreu à presidência pelo Populist Party e teve 150 mil votos. Mas seu maior êxito eleitoral foi chegar a deputado estadual na Louisiana pelo partido Republicano em 1989. Em 1990 ganhou as primarias e foi o candidato republicano a senador. Não ganhou a eleição, mas ganhou entre o eleitorado branco, teve $67 \%$ dos votos neste segmento do eleitorado. Cf. dados em < https://ucsd.libguides.com/c.php?g=90743\&p=586766 > Acessado em 12/09/2019.

17 No debate dos círculos neofascistas, tanto o capitalismo como o socialismo seriam dominados ou mesmo invenção dos judeus.

${ }^{18} \mathrm{Cf}$. dele "Where the Right Went Wrong: How Neoconservatives Subverted the Reagan Revolution and Hijacked the Bush Presidency" (ed. Library Binding, NYC, 2004)

${ }_{19} \mathrm{~A}$ escolha do termo remete propositadamente ao America First Committee, criado por R. Douglas Stuart Jr em 1940. E que investiu em Charles Lindbergh como liderança política. A proposta do grupo era evitar a entrada dos EUA na $2^{\mathrm{a}}$ Guerra e não defendia a simpatia aos Nazistas. 0 proprio Buchanan compartilha desta mesma visão. Cf. dele Churchill, Hitler, and "The Unnecessary War, Ed. Random House, NYC. 2009.

20 Cf. do proprio autor Right from the Beginning, Ed. Regnery Publishing; NYC, 1990.

$21 \mathrm{Em} 2000$ recebeu 448,895 votos.

22 Autor que ascendeu com Nova Direita dos anos de 1970, mas dela se isolou, migrando do conservadorismo para um populismo de apelo racial a partir dos anos de 1990. Sua obra foi resgatada por organizadores "alt-right" como Richard B. Spencer que o considera um pioneiro da "consciência racial branca". Como aponta Matthew Rose, Samuel Francis hoje em dia parece anunciar em sua obra a ascensão de Donald Trump. Cf. em < https://www.firstthings.com/article/2019/10/the-outsider > Acessado em 17/09/2019. 
Buchanan propõe uma nova base política formada por dois pilares: o nacionalismo econômico e a política identitária voltada para a classe média branca, protestante dos EUA.

Nos anos de 1990 teve também grande impacto as obras de Charles Murray e Richard Herrnstein, a Curva de Bell (94) que retomou as teses genéticas para explicar a desigualdade racial nos EUA e a obra de Samuel Huntington, Choque de civilizações (1994) que argumentava por uma nova geopolítica alinhada a questões religiosas e étnicas. Os EUA entraram no século XXI com a questão racial ainda como uma ferida aberta, com medo do declínio do Ocidente, e sobretudo com os conflitos étnicos e humanitários o temor de uma invasão imigrante não para de alimentar a cultura conspiratória.

Com a passagem do século conspirações catastrofistas ganharam força, movimentos religiosos, cultos que pregam o fim dos tempos se misturaram a temas históricos: temor racial, xenofobia, antissemitismo e temor quanto a "nova ordem mundial". Os ataques espetaculares, que o mundo todo assistiu pela TV em 11/09 $9^{23}$ trouxeram novos elementos: a islamofobia, a ideia de que foi uma ação do próprio governo dos EUA além de uma miríade de outras conspirações ${ }^{24}$. Segundo do a SPLC ${ }^{25}$ em menos de 2 décadas grupos de ódio organizados em torno da islamofobia foram de 5 em 2000 para 110 grupos em 2018. E o governo George W. Bush (2001 - 2009) ficou dividido entre a promessa de um governo que implementaria de fato uma agenda conservadora (corte de impostos, combate ao aborto, liberdade religiosa, política externa assertiva) e na prática um governo que aumento de tamanho, passou a ser mais caro e mais intrusivo ${ }^{26}$.

A eleição de Barack Obama em 2008 não pacificou a situação, ao contrário, uma espécie de histeria se espalhou entre os grupos conspiradores, acreditando que Obama seria o anticristo, um ditador que iria confiscar as armas, um socialista, um muçulmano ou mesmo uma fraude. Apesar de popular, Obama teve uma relação conflituosa com a imprensa americana. Casos de espionagem, tanto tendo como alvo a população dos EUA como casos envolvendo líderes mundiais, aumentaram a sensação de um governo inimigo do povo, um dos motes que permeou a organizou do Tea Party. Um movimento com forte viés libertário nos temas econômicos, mas também que se alimentava de teorias conspiratórias dentre elas especialmente a conspiração que pregava ser Obama socialista ou muçulmano ou mesmo ambos. Estas conspirações se descolaram do Tea Party e ganharam força na internet ${ }^{27}$. Os chamados "birthers" acreditavam que Obama além de

${ }^{23}$ Como mostram Sustein e Vermeule (2009) ao citar as pesquisas realizadas pela Zogby Internacional (2004) e pela Scripps-Howerd Pool (2006) 49\% dos habitantes de Nova York acreditavam que o governo sabia previamente dos ataques e $36 \%$ dos habitantes da cidade afirmaram que agentes federais participaram do ataque.

24 Cf. Revisão de algumas das conspirações que cercam os ataques de 11/09/2001 feita por Dave Thomas em < https://skepticalinquirer.org/2011/07/the_911_truth_movement_the_top_conspiracy_theory_a_de cade_later/ > Acessado em 13/09/2019.

25 Cf. em < https://www.splcenter.org/fighting-hate/intelligence-report/2017/year-hate-and-extremism > Acessado em 13/09/2019.

${ }^{26}$ Além de duas guerras no Oriente Médio, e aumento nos gastos militares, Bush criou a Homeland Security e uma série de outras agencias especiais. Para uma discussão mais detalhada conferir de Dana Priest e William M. Arkin, Top Secret America: The Rise of the New American Security State. Ed. Little, Brown, NYC. 2011.

27 Um dos atores virtuais mais relevantes nesta passagem da mobilização real para a virtual foi o comunicador, radialista do Texas, Alex Jones. Com seu portal de notícias Infowars , Jones não só alimentou a conspiração dos birthers e do socialismo na Casa Branca como deu vazão para outras conspirações especialmente aquelas que alegavam que grandes ataques como o 11/09/2001 ou atirados que atacam escolas como o caso da escola elementar de Sandy Cook ou em universidades e espaços públicos seriam uma fraude ou fruto de ação do próprio governo. Jones fez estas alegações por mais de dez anos sofrendo alguma punição apenas em ameados de 2019. Cf. desdobramentos em <https://www.salon.com/2019/ 
muçulmano teria nascido no Quênia. Entre as celebridades que apoiavam os birthers estava Donald Trump que já tinha cogita concorrer em 2000 pelo Partido da Reforma e utilizou este movimento como ponto de apoio para se lançar à presidência pelo Partido Republicano.

Retomando o debate proposto por Snyder (2018) o propósito das mentiras recorrentes se enquadram perfeitamente na lógica da política da eternidade, estruturando um mundo onde a factualidade se torna desnecessária.

Entre os dois mandatos tanto de George W. Bush como de Barack H. Obama se agravou um processo ainda mais antigo, da formação das bolhas ideológicas. As bolhas funcionam como uma espécie de tribalismo da cultura política. Para além de Direita, Esquerda, Conservadores e Progressistas, se cria politicas identitárias que mesclam temas ideológicos com questões demográficas, raciais, de gênero criando uma política de viés identitário. Neste processo a cultura do medo é protagonista, ela cria a exclusão que reafirma o grupo. Neste processo de manipulação dos medos, figuras como Trump usam da emoção, de uma linguagem as vezes agressiva, as vezes de vítima para transitar entre bolhas ideológicas criando uma legião de seguidores, quase "fãs" que o seguiram como presidente tal como seguem uma celebridade das redes sociais da internet.

Para manter sua base mobilizada, Trump usa e abusa de mentiras, e mais do isso joga, alimenta negacionismos e questiona instituições, profissionais e pesquisadores que ousam questioná-lo e defender alguma certeza institucional e a própria ideia de verdade. A tese do declínio da verdade como aponta Kakutani (2018) é mais um dos muitos desdobramentos dos anos de 1960. Tem relação com o desconstrutivismo metodológico de autores como Jacques Derrida e com a anunciação do niilismo como problema da pós modernidade como em Michel Foucault e o mundo de verdades e relacionamentos líquidos de Zygmunt Bauman.

É a própria teoria pós-moderna que muitas vezes é a fonte que negacionistas, manipuladores e propagadores de conspirações e de notícias falas se apoiam para justificar suas estratégias. Em resumo, argumentam que se tudo é narrativa, se tudo é relativo, se nada se concretiza no mundo liquido, então que os argumentos, narrativas, teorias e verdades que propagam sejam o novo consenso, o novo normal, a nova ciência, o novo jornalismo etc. E neste processo, como mostra Rosenblaum (2019) ao estudar negacionistas como do Holocausto ou das Mudanças Climáticas, a lógica é a mesma para o universo das conspirações, aos que acreditam, tudo reforça a crença.

E quando mais o eleitorado manifesta raiva ou medo mais fácil de negar o debate ou mesmo a busca por especialistas. Trump neste ponto se apoio neste imaginado respaldo popular para deslegitimar tanto seus adversários como para se recusar a ouvir ou consultar membros de seu próprio gabinete $^{28}$ e dar atenção apenas a si mesmo ou no máximo a sua família ${ }^{29}$.

O processo decisório, conforme argumenta Kakutani (2018) segue uma lógica de engenharia reversa; em primeiro lugar, a prioridade absoluta é atingir o resultado desejado; uma vez alcançado, se busca as justificativas e explicações necessárias. Não há debate, não coleta de dados, não há formulação ou testes de hipóteses, nem publicidade dos resultados, apenas relação crua e viciada entre fins e meios. E quando o resultado desejado não é atingido ou não produz o impacto esperado, a estratégia neste contexto de pós - verdade é de negar a intenção ou sobretudo negar o fracasso.

09/05/alex-jones-loses-his-appeal-of-sandy-hook-defamation-lawsuit-and-he-has-been-ordered-to-payup/> Acessado em 17/09/2019.

28 Cf. bastidores da Casa Branca de Trump: Fire and Fury; de Michael Wolff, ed. Henry Holt and Company; NYC. 2018.

29 E mesmo dentro da ideia de família, Trump faz distinção entre filhos e entre genro e amigos. 
Ao negar o fracasso mesmo quando ele é evidente e ao afirmar o sucesso, mesmo quando ele não existe mostra uma tentativa perigosa de moldar a racionalidade pela cultura. Em última instância como já deixou escapar Donald Trump, ele gostaria que as pessoas acreditassem nele e somente nele, tal como em outro contexto consegue fazer Kim Jong-um na Coreia do Norte ${ }^{30}$. Trump assim como outros que se alimentam da pós-verdade acredita que, se todos mentem então eles também podem mentir e caso a mentira os ajude a parecer melhores então que assim seja. Não há culpa? Remorso ou mal-estar? Autores como Kakutani (2018) e Nolen Gertz (2018) argumentam que a ideia de "parecer melhor ", de usar filtros ou outros recursos para melhorar fotos é parte da cultural virtual e da vida online uma vida que pode ser de excessos e alimentar o niilismo ambos sintomas de uma crise já percebida fora da internet.

\section{A mobilização via conspirações da The John Birch Society.}

Para trazer uma maior compreensão sobre a questão conspiratória e sua influência na política estadunidense, o objetivo dessa passagem concentra-se em compreender o teor conspiratório presente na forma como a The John Birch Society analisa a questão racial e dos direitos civis nos EUA, trazendo conclusões sobre os caminhos que levaram ao momento atual de pós-verdades.

Como foi apontado na introdução, o mote do pensamento da organização parte da crença na existência de uma infiltração coletivista/comunista nos EUA e no mundo, com o intuito de eliminar deveres e direitos dos indivíduos para ampliar o potencial tirânico dos governantes. Isso se torna visível quando, no filme The Truth in Time, Welch (1966) alinhou o nascimento dessa infiltração à tentativa de implantação de uma nova ordem mundial, articulada desde o século XVIII pelos Illuminati e que ao longo dos anos se transformou nos movimentos comunistas ao redor do mundo. Esse movimento seria responsável pelas principais revoluções e guerras ocorridas no planeta, o que acontecia sempre em nome da inserção de uma ideologia coletivista e sobre o pretexto de valores humanitários. Dentro dessa leitura, a Revolução Francesa, os movimentos de trabalhadores, a Revolução de 1848, a Revolução Russa, as duas grandes guerras mundiais e, até mesmo, transformações em legislações estadunidenses eram compreendidas como reflexos da manipulação dessa elite invisível e de sua tentativa de corromper valores ocidentais.

Para isso, seus membros forçavam os conflitos e o dissenso ao longo da história, com o intuito de motivar eventos que iam da invasão da Polônia, pela Alemanha durante a Segunda Guerra Mundial, até as legislações contra a segregação nos estados do sul dos EUA durante os anos 1950. No lado oposto a essas lideranças conspiratórias estaria o homem comum, religioso, trabalhador, respeitador das regras e defensor da família, que seria constantemente influenciado e iludido por ideais coletivistas que o acostumava a uma vida de dependência cada vez maior ao governo.

A partir da leitura do seu material, percebe-se que o líder da The John Birch Society compreendia que a própria formação da URSS era resultado de uma conspiração maior e tinha em seu intuito construir um Estado forte que centralizasse os ideais desse grupo e que durante o governo de Joseph Stalin se reforçou como principal rival e alternativa a republica constitucional existente nos EUA. Contudo, embora existisse uma oposição militar declarada entre as duas superpotências, Welch percebia que, mais perigosa do que a possibilidade de uma Guerra entre elas, estava a "estratégia leninista" de expansão através da manipulação, que ocorreria sem que existisse a

$30 \mathrm{Cf}$ < https://thehill.com/homenews/administration/392430-trump-i-want-americans-to-listen-to-me-likenorth-koreans-listen-to > Acessado em 16/09/2019. 
necessidade de tropas soviéticas participassem de combates. Ou de acordo com a fala de Welch (WELCH, 1963, p.17): “Agora por favor notem, senhores, que o Comunismo nunca teria alcançado qualquer do seu imenso progresso pelo uso direto da força”.

Welch (1963) apontou a existência de três estratégias utilizadas pelos soviéticos para alcançar o controle de novas regiões: a primeira seria incluir agentes em posições de poder para conseguir alcançar um golpe de Estado pacífico. A segunda ocorreria através do fomentar conflitos, colocando os grupos uns contra os outros. Já a terceira consistiria em ir minando os valores do país a ser dominado, motivando a população a uma dependência cada vez maior de um estado centralizador.

Esse processo viria da fomentação de contradições e das rivalidades nas sociedades alvo e resultariam em tentativas de implantação de experiências e políticas que privilegiassem o coletivismo $^{31}$, que abolissem a livre iniciativa ou que levassem a processos revolucionários. Dentro desse cenário, para a JBS, o establishment liberal que dominava os EUA desde a década de 1930 estava repleto de conspiradores infiltrados ou de indivíduos iludidos pela força ideológica dessa conspiração, que constantemente tomariam decisões que privilegiariam o fortalecimento de governos e a cisão entre grupos. Assim, os anos 50 e 60 são marcados por dois debates essenciais: o fim da segregação racial e o apogeu dos movimentos pelos direitos civis.

O primeiro, que se concentrava na questão do fim da segregação, é compreendido pela organização como uma tentativa centralizadora do Governo Federal de interferir na liberdade dos indivíduos, organizações e estados de decidir quais os espaços seriam obrigatoriamente compartilhados e quais não. É importante notar que após o caso Brown v. Board of Education of Topeka aflorouse uma nova onda de ressentimento racial branco, muitos deles pregando a supremacia branca e teorias de degeneração racial dos negros. O crescimento desses movimentos ampliava a sensação de insegurança e despertava narrativas sobre uma possível guerra civil racial nos estados do sul.

A JBS flertava com esse cenário e tentava descolar sua imagem dos movimentos da direita radical, como a KKK, neonazistas e outros supremacistas brancos, para isso, inseria em suas posições argumentos mais "sofisticados" que negavam diferenças raciais biológicas e que possibilitavam um maior engajamento por parte da sociedade e uma maior facilidade de mobilização por parte de seus membros. Como exemplo, destaca-se o documento do FBI (1965), publicado em 20 de janeiro de 1965, que identificava a tentativa falha Klan de ampliar sua atuação em Charlotte, estabelecendo uma coalizão com a JBS. Nesse documento fica claro que os membros da JBS não gostariam de ser associados a Klan por causa do extremismo da organização, ao mesmo tempo em que, membros da KKK se sentiam desconfortáveis com o que eles enxergavam como imoralidades presentes nos membros da JBS, com o consumo de bebida e a presença nas fileiras da organização de judeus, negros e católicos.

Welch se posicionava de maneira contrária tanto ao governo federal decidir sobre a integração, quanto pela segregação. Para ele, indivíduos e companhias tinham o direito de contratar quem melhor the conviessem e organizações e clubes deveriam poder escolher qual seria o seu público alvo. Ou seja, a escolha pela segregação ou não estaria limitada apenas ao âmbito local/individual.

Dentro desse cenário, os membros da organização constantemente reforçavam a presença de afro-americanos entre as suas fileiras, inclusive com dois de seus comitês sendo compostos exclusivamente por negros. Além disso, defendiam a ideia de que existia ascensão social entre o

31 Thompson (2007). 
grupo étnico através do processo de assimilação pela sociedade. Para justificar essa fala, eles citavam o aumento no número de afro-americanos que se tornavam doutores ao longo dos anos. Isso representaria que questões como o racismo estariam se diluindo ao longo do tempo e, em consonância com essa perspectiva, quanto menos conflitos a sociedade passasse, mais rapidamente ela conseguiria resolver os "problemas raciais".

No auge do debate em torno da questão da segregação, Welch (1963) posicionou o presidente Eisenhower como figura chave da conspiração comunista. O presidente republicano seria um dos infiltrados e teria enviado a guarda nacional para combater os protestos em torno da questão da segregação/integração com o intuito de gerar violência e medo, o que teria motivado a Suprema Corte a acelerar as decisões sobre o tema. O líder da JBS defendia a existência de uma aliança entre o presidente e as redes de comunicação para fomentar o sentimento de descontrole, o que seria reforçado, logo em seguida, pelas críticas realizadas por Eisenhower a forma de atuação da polícia e da Guarda Nacional nos eventos. Ao mesmo tempo, a JBS mobilizava suas fileiras em uma campanha para o impeachment do chefe de justiça Earl Warren por estar à frente das decisões em torno do debate sobre o fim da segregação no país. Segundo a reportagem de Broder (1961), membros da JBS o acusavam de, em um total de 39 decisões, tomar 36 voltadas ao interesse comunista no país.

Mas uma vez aqui, a JBS entendeu que todos os episódios que envolveram a questão da decisão pró-integração eram calculados, com o intuito de estimular o ressentimento e acentuar as diferenças entre os grupos raciais, o que facilitaria uma futura vitória soviética no país.

Relacionado a esse cenário, pode-se destacar o segundo ponto de interesse dessa passagem do artigo, a análise sobre a leitura da organização a respeito dos movimentos pelos direitos civis. Grupp Jr. (1971) mostrou que entre os membros da organização existia a crença de que o programa da JBS conseguiria demonstrar a fraude em torno dos movimentos pelos direitos civis.

Para que isso fique mais claro, é importante observar o material presente no documentário Anarchy, U.S.A. (1966) Welch e a JBS compreendiam que os conflitos gerados nos campi universitários e que se estenderam em ondas de violência nas cidades eram a porta de entrada para uma futura revolução comunista no país. Como forma de demonstrar isso, o filme, financiado pela JBS, comparava a questão racial nos EUA aos eventos ocorridos em outros países como a revolução cubana, a independência da Argélia e a revolução comunista na China. Para a organização, todos esses eventos partiam de alguns estágios essenciais: 1- estimular a divisão. 2- Criar a sensação de apoio popular, 3- eliminar ou descredibilizar os opositores. 4 criar a aparência de revolução.

Dentro dessa lógica, o segredo para a implantação do comunismo estava em exatamente negar que o objetivo dos movimentos era a sua implantação. Para a JBS isso ocorreu em todos os exemplos citados acima e em essência sempre sob o argumento de grupos que eram explorados, tiranizados ou que não tinham seus direitos respeitados. Com isso, os movimentos pelos direitos civis nos EUA representavam a tentativa de cooptação a causa soviética e culminariam, ao longo do tempo, como apontou Verhoeven (2015), na fundação de uma República soviética negra no sul estadunidense, que teria Atlanta como sua capital e Martin Luther King Jr. como seu presidente. Em Anarchy, U.S.A. (1966) a possibilidade de implantação do comunismo nos EUA poderia vir tanto através da fomentação da luta de classe entre proletários e burgueses, quanto através do embate racial e na consequente separação do país em dois. Essa estratégia era reforçada pela fala de negros, ex-membros do Partido Comunista, Leonard Patterson e Julia Brown, que assumiam ter participado de reuniões que estimulavam a formação de dissenso entre os grupos raciais no país.

Embora dotada de um alto grau conspiratório, a organização reforçava a inserção de suas 
ideias com uma estratégia em etapas. Primeiro lançavam a imagem conspiratória através do discurso de algum de suas lideranças ou porta-vozes sobre algum evento de impacto, para, em seguida, mobilizar seus comitês locais para replicarem a teoria. Em sequência, com a visibilidade advinda do evento e da fala das lideranças, eram financiadas campanhas de apoio a temas de interesse da JBS e para o cadastramento de novos membros. Essa estratégia da JBS teve um papel importantíssimo na construção da nova direita estadunidense, uma vez que, lançava simultaneamente, o medo dos levantes raciais e atacava o establishment liberal de governos como o de Kennedy e Lindon Johnson associando-os aos possíveis interesses do comunismo.

Entre essas campanhas destaca-se o movimento iniciado em 1964 intitulado "support your local police" que estimulava, através de suas unidades locais, uma campanha de apoio aos policiais que em meio aos confrontos vinham sendo pressionados pelas lideranças dos movimentos por direitos civis e pelo governo federal ${ }^{32}$. Segundo outro documento do FBI (1964) presente na Ernie Lazar Collection, algumas lideranças e ativistas estavam infiltrados em meio a movimentos por direito civil de caráter pacíficos e em meio as manifestações chutavam os cães policiais estimulando assim o confronto e jogando a população contra os policiais.

Junto a isso, as principais lideranças dos movimentos pelos direitos civis eram consideradas como indivíduos treinados pelos soviéticos para conseguir estabelecer a revolução pregando a não violência, motivando reação por parte de grupos ligados a direita radical e através da visibilidade dos ataques sofridos por eles trazerem ganhos para os interesses soviéticos. A partir dessa leitura o próprio Martin Luther King Jr. teve sua imagem associada ao Partido Comunista e sua morte foi considerada pela Birch como o sacrifício de um mártir para a causa comunista.

A estratégia da JBS manteve bastante força até a campanha de Barry Goldwater em 1964, conseguindo de 1958 até 1964 permanecer como a principal organização da direita no país. Com a aliança em torno da campanha do senador republicano, as novas organizações que surgiam a partir dela, acusavam Welch de extremismo e passaram a isolar o grupo em prol da estratégia de dominância do Partido Republicano. As constantes acusações de fazer parte da conspiração comunista por parte da organização a figuras de proeminência no país, fizeram com que a opinião pública e as instituições concentrassem seus olhares sobre as atividades da organização que embora ainda mantenha seu funcionamento, já no final dos anos 1960, passou por uma perda vertiginosa de membros e apoiadores.

Ao abordar a trajetória da JBS durante o período se mostra interessante, visto que, muitas das características apresentadas por Welch e pela organização continuam presentes até os dias atuais na política americana. Para além da ideia de conspiração presente no entendimento de forças obscuras que tentariam desestabilizar o país, destacam-se o caráter narcisista e centralizador de Welch e Trump, ambos colocando-se na história como as únicas figuras capazes de entender as necessidades da população. Junto a isso, percebe-se a recorrente cartada reacionária de defesa de um espaço mítico, onde, a sociedade estadunidense era menos conflituosa. Dentro dessa perspectiva, a luta por direitos sociais, a presença de novos grupos e a visibilidade de sua cultura e a própria oposição a qualquer ideia dessas lideranças estariam atreladas a interesses invisíveis e que, consequentemente, serviriam para diminuir o poder da população branca e protestante responsável pela posição de dominância alcançada pelo país.

32 Segundo a reportagem de Foster (1964) in JBS-Boston -1. 


\section{A Mobilização Via Medo: Da Segregação racial nas Escolas ao Muro na Fronteira com o México.}

Vimos até aqui como a conspiração foi protagonista para a mobilização anticomunista suscita pela The John Birch Society (JBS). Veremos nesta sessão outro aspecto central para o conservadorismo pré-1960, a cultura do medo cujo protagonismo esteve com a The Citizens' Councils para em seguida entendermos como Trump retoma estas tradições.

The Citizens' Councils (CCs) surgiu em 1954 em Indianola, Mississippi. O grupo nasce organizado por Robert B. Patterson, um administrador de fazenda do Mississippi a partir de um manifesto escrito pelo juiz Tom P. Brady, intitulado Black Monday. Neste manifesto, Brady ataca a Suprema Corte após a decisão Brown v. Board of Education of Topeka (1954) que declara ser inconstitucional a segregação racial nas escolas públicas. A decisão também afetava as escolas particulares que, em muitos casos, serviam como válvula de escape para os segregacionistas que conseguiam se isolar em escolas homogêneas como alternativa as escolas públicas. Para todos os fins, a segregação tornou-se proibida após esta decisão.

A CCs destacou-se pela sua rápida organização e crescimento. Tornando-se em menos de 10 anos o maior lobby político pró-segregação dos EUA. Com financiamento que vinham parte de filiados e parte do estado do Mississippi ${ }^{33}$, o CCs montou uma estrutura que consistia em uma revista a The Citizen, um programa na TV local, chamado Forum, além de organizar eventos de "lideranças" que reuniam até 2 mil pessoas com delegações e representantes de 19 estados $^{34}$.

Como nos mostra Rolph (2018), o CCs teve três momentos distintos ao longo de seus 35 anos de vida. O primeiro deles foi de 1954 a 1957 centrado na cultura do medo, alarmando os riscos e as consequências de uma educação integrada. Um segundo momento de 1958 até meados dos anos de 1960, no qual o grupo ganhou dimensão nacional e tornou-se uma espécie de lobby político forte no Sul dos EUA, mas presente também em outros estados e em Washington D.C. E um terceiro momento dos anos de 1970 até seu fim em 1989 quando o grupo entrou em declínio, voltando-se nos anos 70 para a política local do Mississippi e nos anos 80 para a defesa de "minorias brancas" e de regimes como o Apartheid na África do Sul.

Em seu auge entre 1954 e 1664 a CCs ajudou a eleger governadores em estados sulistas ${ }^{35} \mathrm{e}$ buscou uma forma de pressão e de luta política que o diferenciava de grupos violentos, especialmente o KKK. O CCs orgulhava-se de receber "doutores", "advogados", “atletas" e comerciantes de prestígio local em suas reuniões e eventos. A defesa da segregação era intelectual, política, como um lobby, um grupo de pressão que pretendia mobilizar e organizar uma "resistência branca"36" contra a revolução e a "violência" dos negros e seus aliados que falavam em direitos civis.

O CCs argumentou de muitas formas pela defesa da segregação. Para fins didáticos e de

\footnotetext{
33 Via Mississippi State Sovereignty Commission, uma agência estatual que existiu entre 1956 e 1977.0 objetivo esta agência era financiar projetos e movimentos que fortalecem a soberania subnacional, o poder dos Estados contra interferências da União.

34 Cf. The Citizen, V.10, N. 07, Abril de 1966. Disponível em acervo online < http://clio.lib.olemiss.edu/ cdm/landingpage/collection/citizens > Acessado em 24/10/2019.

35 Especialmente no Mississippi, com Ross Robert Barnett (1960-1964) e no Alabama com George Wallace (1963-1967). Wallace também teve o apoio do CCs quando lançou -se a presidência em 1968 e 1972.

36 A expressão aparece recorrentemente nos editorias do jornal The Citizen. E em panfleto divulgado em 1972, intitulado It's Your Fight, Too! O CCs alerta que em muitas cidades do Mississippi a população branca era minoritária e que se não se organizasse e criasse uma força de resistência o caos seria inevitável. cf. em < http://clio.lib.olemiss.edu/cdm/compoundobject/collection/citizens/id/1662 > Acessado em 24/10/2019.
} 
síntese para este artigo, organizamos os argumentos em três grandes grupos ${ }^{37}$ : o argumento jurídico com foco no direito dos Estados e soberania local; o argumento do medo e os argumentos pseudocientíficos.

\section{Quadro 1 - Argumentos Jurídicos}

Toda soberania é unitária e portanto indivisível. Não cabe a União o poder de interferir na soberania dos Estados.

Lutar contra a integração é uma luta patriótica.

A ideia de Integração seria parte de uma agenda estatista que propõe ampliar politicas de Bem-Estar Social, criando cidadãos totalmente dependentes do governo.
Famílias brancas não podem ser obrigadas a matricularem seus filhos em escolas integradas.

Organizações que defendem os Direitos Civis com a American Civil Liberties Union (ACLU) glorificam a violência dos negros e condenam a ação da polícia que age pelo bem comum e zela pela lei e ordem.

Defender os Direitos Civis seria defender algo estranho aos valores e a tradição política dos EUA.

Quadro 2 - Argumentos que alimentam a Cultura do Medo.

A integração seria o Paraíso Perdido tal como descito na obra de John Milton.

Ao impor a Integração, a União estaria impondo também o ateismo.

\section{Tal como o trauma do período da Reconstrução pós Guerra Civil. 0 periodo dos Direitos Civis ( 1954 - 1964) seria uma segunda Reconstrução.}

Os negros farão mais e mais manifestações violentas até a total destituição dos EUA.
Ao forçar a Integração, a União estaria na verdade forçando a mistura racial nos EUA.

\section{O Estado alega ter a Opinião Pública} a seu lado. Mas quem controla a Opinião Pública?

Quadro 3 - Argumentos Pseudocientíficos

A Integração seria uma forma de
nivelar a educação para baixo.
Estudantes negros seriam
intelectualmente inferiores aos
brancos

Negros lidam intensamente com as emoções. Tem temperamento, inteligência e comportamento distintos dos brancos.
A política dos Direitos Civiis seria na veradde uma forma dos Democratas criarem uma balança racial nos EUA mais favorável eleitoralmente.

Negros são primitivos, capazes de atos de violência impusiva e são naturalmente desobedientes.
Ao contrário do que imagina o governo, o contato de brancos com negros apenas aumenta a "consciência racial" dos brancos.

Negros se apoiam no complexo de culpa de alguns brancos para impor sua agenda.

OS EUA como nação seria - por definição - uma nação de brancos. Raça e cidadania nao podem ser separados.

Em seu estudo sobre a era da segregação $(1890$ - 1940) nos EUA, Hale (1995) argumentou que o CCs ao antagonizar com o movimento pelos direitos civis buscou um renascimento da ideia de Supremacia Branca. A partir do final dos anos de 1960, o CCs era conhecido também pelos seus

37 Todos estes argumentos foram tirados do acervo disponível em < http://clio.lib.olemiss.edu/cdm/compoundobject/collection/citizens/id/1662 > . Do jornal The Citizen, pesquisamos nos seguintes exemplares: nov./61; set/64; jan./66; maio/66; junho/66; março/70; jan./71; dez./74; abril/75; 
detratores como "White Citizens' Councils" o que enfatizava uma "causa" racial branca. Esta luta maior seria uma bandeira que o CCs herdou e apenas passou para frente. Ao perder a batalha da integração nas escolas, a guerra passou a ser global e muitos outros grupos de "supremacia racial branca" que acreditavam estar em plena "guerra racial" surgiram nas décadas seguintes.

A estratégia de luta local dentro de uma guerra racial reapareceu no governo Trump em primeiro mandato, quando por exemplo em Charlottesville (Virginia) ocorreu o evento Unite the Right Rally. Sob o pretexto de protestar contra a proposta de remoção ${ }^{38}$ de uma estátua do general (dos Confederados) Lee, um símbolo cultural da Guerra Civil, estavam ali diferentes grupos que defendem a supremacia racial branca e agem como "patriotas" numa guerra racial. Tal como o CCs nos anos de 1960 o evento contou com a anuência de políticos, o movimento contemporâneo também tem o apoio - mesmo que velado - da presidência da República.

Como argumentou Hale (1995) a ideia de segregação é uma ideia que seduz certos políticos por ser uma forma de dividir o eleitorado e encontrar nichos mais homogêneos. E o recorte racial perpassa outras formas de identidade como de gênero, de etnicidade, de classe, de origem e de religião. A ideia de uma raça ou identidade a partir da raça cria uma coletividade mais homogênea que pode significar politicamente um apoio de votos solido. George Wallace com o famoso discurso que fez quando assumiu o governo do Alabama (1963) e depois o repetiu como candidato à presidência em 1968: "Eu traço a linha na poeira e jogo a luva diante dos pés da tirania (. . .) e eu disse (. . .) segregação hoje (. . .) segregação amanhã(. . .) segregação para sempre ${ }^{39}$ ". Wallace teve quase 10 milhões de votos na eleição de 1968 ganhando com larga margem nos estados do Alabama, Mississippi e Louisiana.

Em 2016, reagindo ao evento que uniu movimentos de supremacistas brancos, Unite the Right, o presidente Trump disse condenar nazistas, fascistas e extremistas, mas também, disse ver pessoas boas nos dois lados $^{40}$ e que defender a estátua e memória do General Lee era "uma coisa boa" e comentou que muitos generais que conheceu na Casa Branca diziam que o General Lee era recorrentemente citado como um dos favoritos.

Trump também retoma a cultura medo e a torna mais enfática quando o assunto é política migratória e a fronteira dos EUA com o México. Como argumentaram Dentice e Willians (2010), uma estratégia recorrente de movimentos racistas e extremistas a partir dos anos de 1990 era focar sua retórica no sentimento anti-imigrantes. Ao atacar a imigração como o problema nacional, grupos que defendem bandeiras de superioridade racial e de guerra racial conseguem chegar a um público maior, se mostrando atrativo até mesmo para um eleitor que se afirme como moderado.

38 Este debate sobre estatuas ocorreu desde 2016 e em muitas cidades americanos e campus universitários a uma revisionismo e debate quem é homenageado em estátuas, prédios públicos e espaços universitários. Ver em debate com o historiador David Blight em < https://www.youtube.com/watch?v=rGeVI3nEJY\&list=WL\&index=11\&t=0s > Acessado em 24/10/2019.

39 No original $<$ I draw the line in the dust and toss the gauntlet before the feet of tyranny . . . and I say . . . segregation today . . . segregation tomorrow . . . segregation forever. Integra do discurso em < https://www.blackpast.org/african-american-history/speeches-african-american-history/1963-georgewallace-segregation-now-segregation-forever/ > Acessado em 24/10/2019.

$40 \mathrm{Em}$ referência também aos que estavam em Charlottesville protestando contra o evento. Uma pessoa morreu atropelada por um supremacista branco. Trump não se referiu a esta morte. Cf. declaração na integra em < https://oglobo.globo.com/mundo/charlottesville-11-comentarios-de-trump-sobre-conflito-racial-21711452 > Acessado em 25/10/2019. Posteriormente em 2019, já em campanha para reeleição, assessores de Trump declararam que a reação de Trump ao Unite the Right Rally foi um dos piores momentos da presidência e tentaram reinterpretar o que o presidente disse, desta vez culpando a "interpretação" errônea que a mídia fez. Cf. em < https://www.prageru.com/video/the-charlottesville-lie/ > Acessado em 26/10/2019. 
O argumento contra a imigração cria a ideia de uma nação que precisa se unir contra o risco de uma "invasão" ${ }^{41}$ ", seja de uma "cultura alienígena" seja de uma religião "que nos odeia ${ }^{42 "}$ ou de pessoas que seriam "criminosos, estupradores ${ }^{43}$ ou, no limite, que irão roubar "nossos" empregos $^{44 "}$. Deste ponto é possível entendermos a estratégia de políticos populistas que se colocam como um defensor e uma voz de um povo cuja vontade está acima de tudo (acima das leis, das regras, das instituições, etc.). Ao projetar este povo automaticamente o líder populista projeta também seus inimigos e estes inimigos são o elemento central da lógica política populista.

\section{Conclusão}

A proposta deste artigo foi discutir organizações de perfil populistas/americanistas dos anos 1950 e 1960, com atenção especial a Citizens Councils e da The John Birch Society (JBS). Estas organizações nos mostraram como essas retóricas historicamente disseminaram e propagaram teorias conspiratórias, especialmente, voltadas para os temas de raça, ordem social e identidade. Sua relevância está em demonstrar que a partir de uma crescente capacidade de ramificação e alcance os dois grupos atingiram um público considerável, denunciando um suposto "governo global" nos anos 1950 e 1960 a partir de uma narrativa que incluía superioridade racial, anticomunismo, direito dos estados e individuais e de uma solução "americanista" para o embate nacional entre liberais e conservadores. Trump surgiu em 2015/16 como uma espécie de americanista/populista disposto a ganhar o eleitorado do Partido Republicano, que numa trajetória de 50 anos tem se consolidado como uma base disposta a votar em candidatos conservadores. A retomada que Trump faz da agenda tanto da JBS como da CCs nos ajuda a entender sua plataforma política e sua falta de afinidade ideológica com o conservadorismo moderno dos EUA.

Os cientistas políticos Barber e Pope (2019) analisam duas pesquisas quantitativas grandes sobre o perfil ideológico do eleitorado que apoio e votou em Trump. Uma pesquisa de 2016, realizada pela Cooperative Congressional Election Study e outra de 2017 realizada pelo site de pesquisa

41 Durante a campanha em 2016, Trump divulgou em redes sociais, vídeos que originalmente eram de marroquinos e pessoas do Magrebe tentando passar para o lado espanhol/europeu do muro como sendo da fronteira dos EUA com o México. Ver compilação de referências a "invasão de imigrantes" em < https://www.theguardian.com/us-news/2019/aug/05/trump-internet-facebook-ads-racism-immigrant-invasion > acessado em 24/10/2019.

$42 \mathrm{Em}$ resposta às críticas de deputadas como Ilhan Omar (nascida na Somália), Alexandria Ocasio-Corte (nascida nos EUA mas filha de Porto-Riquenhos), Ayanna Pressley (negra) e Rashida Tlaib (muçulmana), Trump declarou em sua conta (com mais de 30 milhões de seguidores) numa rede social: "Tão interessante ver as mulheres democratas do Congresso "progressistas", que originalmente vieram de países cujos governos são uma catástrofe completa e total, a pior, a mais corrupta e inepta em qualquer lugar do mundo (se é que eles têm um governo em funcionamento), agora em voz alta. (...) Por que elas não voltam e ajudam a consertar os lugares totalmente destruídos e infestados de crimes de onde vieram? E então voltem e nos mostrem como fazer (...)". Ver compilação das mensagens em inglês em < https://www.vox.com/2019/7/15/20694616/donald-trump-racist-tweets-omar-aoc-tlaib-pressley> Acessado em 24/10/2019.

43 No começo de seu mandato, em fevereiro de 2017, Trump atacou o México, afirmando que o país envia aos EUA “bad hombres" Cf. em < https://www.politico.com/story/2017/02/trump-threatens-mexico-overbad-hombres-234524 > Acessado em 24/10/2019. Em outros momentos durante a campanha entre 2015 e 2016, se referiu a imigrantes mexicanos como criminosos e estupradores, ameaçando enviar tropas militares para a fronteira. Cf. compilação destas declarações em < https://www.bbc.com/news/video_and_audio/headlines/37230916/drug-dealers-criminals-rapists-what-trump-thinks-of-mexicans > Acessado em 24/10/2019.

44 Trump de certa forma resume sua plataforma como "America First" o que está há um passo da retórica segregacionista que nos fala Hale (1995): "american jobs for american workers" ou a ideia recorrente no discurso do CCs: Integração não só é indesejável como impossível” 
YouGov. Os resultados mostram que o eleitor que vota motivado por uma agenda conservadora não escolheu Trump nas primárias, mas o apoiou na eleição geral. Outro ponto central desta pesquisa constata que o eleitor que apoio Trump desde do início, tanto nas primárias como na eleição geral, é um eleitor majoritariamente mais velho, e que se diz "conservador" mas que quando convidado a definir este "conservadorismo" não consegue se expressar ou ir além de ataque aos Democratas em particular ou aos liberais / esquerda de forma mais ampla. A parcela que melhor soube explicar o que seria "conservadorismo" foi justamente o grupo de eleitores que rejeitou Trump desde do início, que os autores classificam como "Never Trump" e que seria também a parcela mais moderada do eleitorado ainda disposta a votar no Partido Republicano.

Trump ao contrário de todos presidenciáveis desde Barry Goldwater (1964) foi um candidato que abriu mão do eleitorado moderado. No caso da eleição de 2016, segundo Barber e Pope (2019), foi uma perda de 10\%, o que significa em termos práticos que 1 a cada 10 que votou nas primárias republicanas depois decidiu por não votar em Trump na eleição geral ${ }^{45}$. Mas a pesquisa também mostrou que ao contrário de Goldwater, o primeiro candidato republicano que propõe uma agenda conservadora sem concessões, Trump em termos ideológicos seria descompromissado. De um conjunto de 10 temas associados ao eleitor conservador, Trump é associado pelas pesquisas há apenas 2 temas: impostos e imigração. E muitas vezes por defender políticas protecionistas e por ter um perfil autoritário, Trump tem dificuldade de se apresentar ao eleitor conservador formado pela Nova Direita desde dos anos de 1960.

O diferencial de Trump é sua capacidade de atacar seus opositores, principalmente ao ser agressivo contra os Democratas. Em síntese, Trump se apresenta genericamente como "conservador" e agressivo contra e ao atacar liberais/a esquerda e seus próprios detratores dentro do partido republicano.

Esta combinação que o elegeu e a cultura do medo e a manipulação das conspirações, rejeitados pela Nova Direita, mas que sempre reclamaram seus espaços dentro do conservadorismo americano, como mostramos, são para Trump novamente os instrumentos para sua sustentação política. Trump não repetirá Wallace: "segregação hoje (. . .) segregação amanhã (. . .)" mas seguirá expressando -se de forma vaga, manipulando a verdade e seu eleitorado.

\section{Fontes}

FBI. _- 20 de janeiro de 1965 Charlotte- 3, p.117-121. Ernie Lazar Collection. 06 de Abril de 1964 HQ33, p.23-27 Ernie Lazar Collection.

University of Mississippi Digital Collections: Special Collections: Citizens' Council Collection. Disponível em < http://clio.lib.olemiss.edu/cdm/landingpage/collection/citizens > Acessado em 24/10/2019.

WELCH, R. The Politician. A look at the political forces that propelled Dwight David Eisenhower into the presidency. Appleton: Robert Welch University Press, 2002.

The Blue Book of The John Birch Society. Los Angeles: Western Islands Publishers, 1961. The Truth in Time. John Birch Society, 1966.

\footnotetext{
45 A título de comparação o artigo mostra que no caso tanto de John McCain (2008) como de Mitt Romney (2012) a perda foi de 1\%. Um a cada 100 eleitores que votou nas primárias republicanas deixou de votar no candidato vitorioso na eleição geral.
} 


\section{Referências Bibliográficas}

BARBER, Michael; POPE Jeremy C. Conservatism in the Era of Trump. Perspectives on Politics. September 2019 | Vol. 17/No. 3.

BLACKWILL, Robert D. (org.) Trump's Foreign Policies are Better Then They Seen. CFR Report n. 84. Abril/2019.

BERLET,Chip; LYONS, Matthew N. Right-Wing Populism in America: Too Close for Comfort. Ed. The Guilford Press, NYC. 2000.

BEYDOUN, Khaled A. American Islamophobia. Ed. University of California Press, Los Angeles. 2018. BRODER, D. S. Birch Groups Sees Gain From Debate Publicity. The Sunday Star, 2 de abril de 1961. BUNDSCHU, B. Churches, Ike and Warren Have Been Birch Targets. The Washington Dally News. 30 de mar. de 1961.

CAREW, Kathryn L.; ROMANO, Stephanie Kelley. Make America Hate Again: Donald Trump and the Birther Conspiracy. Journal of Hate Studies, V.14, N.33. Gonzaga University, WA. 2018.

CITTON, Yves. The Ecology of Attention. Ed. Politily, NYC. 2018.

DENTICE, Dianne (Org.). Social Movements: Contemporary Perspectives. Ed. Cambridge Scholars Publishing, NYC. 2008.

DIAMOND, Sarah. Roads to Dominion: Right-Wing Movements and Political Power in the United States. Ed. The Guilford Press, NYC. 1994.

GERTZ, Nolen. Nihilism and Technology. Ed. Rowman \& Littlefield International, NYC. 2018.

GRIFFIN, E. (dir.) Anarchy, U.S.A. John Birch Society, 1966.

GRUPP JR., F. W. Personal Satisfaction Derived for Membership in the John Birch Society. The Western Politics Quarterly, vol.24, n. 1, March, 1971, p.77-83.

HALE, Grace Elizabeth. Making Whiteness: The Culture of Segregation in the South, 1890-1940. Ed. Vintage, NYC. 2010.

JONES, Bruce; TAUSSIG, Torrey (Org.). Democracy \& Disorder. Projeto de parceria entre a CFR e o Brookings. Fevereiro de 2019.

KAKUTANI, Michiko. A morte da verdade: Notas sobre a mentira na era Trump. Intrínseca. SP. 2018. LANE, Robert E. Political Ideology: Why the American Common Man Believes What He Does. New York: Free Press. 1962.

MULLOY, D. J. The World of the John Birch Society. Conspiracy, Conservatism, and the Cold War. Nashville: Vanderbilt University Press, 2014.

MÜLLER, Jan-Werner. What Is Populism? Ed. Penguin, NYC. 2017.

MURRAY, Charles; HERRNSTEIN, Richard J. The Bell Curve: Intelligence and Class Structure in American Life. Ed. Free Press, NYC. 1994.

SCHLAFLY, Phyllis. A Choice Not an Echo. Ed. Vintage, NYC, 1964.

SEN, Amartya. Identity and Violence: The Illusion of Destiny. Ed. Penguin, NYC. 2015.

SMOOT, Howard. The invisible government. Ed. Western Islands, Boston. 1962. Disponível online em <https://archive.org/details/invisiblegovernm00smoo/page/n3> Acessado em 28/10/2019. STONE, B. S. The John Birch Society: A Profile. The Journal of Politic. Vol. 36, n.1 (Feb. 1974), p. 184-197.

TETRAULT, Justin Everett Cobain. What's hate got to do with it? Right-wing movements and the hate stereotype. Current Sociology, Abril 2019. 
THOMPSON, M. J. Confronting the New Conservatism. The Rise of the Right America. New York: New Your University Press, 2007.

True North: The Principles of Conservatism. The Heritage Foundation. Set. /2019. Disponivel em < https://www.heritage.org/truenorth > Acessado em 25/10/2019.

RILLEY, Dylan. What is Trump? New Left Review n. 114; dez. 2018.

ROSENBLUM, Nancy L; MUIRHEAD, Russell. A Lot of People Are Saying: The New Conspiracism and the Assault on Democracy. Ed. Princeton University, NYC. 2019.

ROLPH, Stephanie R. Resisting Equality: The Citizens' Council, 1954-1989. Ed. LSU Press, NYC. 2018.

SUSTEIN, C. R., VERMEULE, A. Conspiracy Theories: Causes and Cures. The Journal of Political Philosophy. Vol. 17, n. 12, Jun. 2009, p. 202-207.

SNYDER, T. Na Contramão da Liberdade. A guinada Autoritária das Democracias Contemporâneas. Trad. Berilo Vargas. Companhia das letras, São Paulo, 2019.

VERHOEVEN, B. L. The rearguard of freedom: The John Birch Society and the development of modern conservatism in the United States, 1958-1968. Tese: University of Nottingham, 2015.

VYSOTSKY, Stanislav; MADFIS, Eric. Uniting the Right: Anti-Immigration, Organizing, and the Legitimation of Extreme Racist Organizations. Journal of Hate Studies V. 12, N. 1. 2016.

WILCOX, C. Sources of Support for the Old Right: A Comparison of the John Birch Society and the Christian Anti-Communism Crusade. Social Science History. Vol. 12, n.4 (Winter, 1988), p. 429449.

Artigo recebido em: $31 / 10 / 2019$

Artigo aceito em: 10/02/2020 